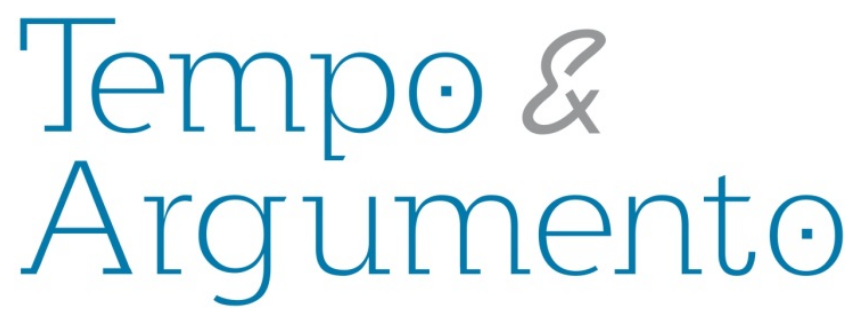

\title{
Uma filosofia do futuro? Robert James Maddox e a sua perspectiva sobre a bomba atômica
}

\begin{abstract}
Resumo
Qual a função e o sentido do "futuro" na História? Esta pergunta pode ser respondida neste artigo a partir da perspectiva historiográfica de Robert James Maddox. Esse historiador ortodoxo estadunidense dedicou boa parte de sua vida acadêmica aos estudos sobre a bomba atômica e a descontruir os "mitos" daqueles que contestavam o uso das bombas nucleares por parte dos EUA. Argumentando que Maddox opera num sentido que tenta ver uma unidade no passado estadunidense frente a um presente ainda mais fragmentado, a função que o futuro passa a exercer em sua narrativa é de justificativa. Neste sentido, pode-se pensar que o fazer historiográfico de Robert Maddox e a sua tentativa de comprovar (empiricamente e retoricamente) a necessidade do uso das bombas atômicas fez com que ele usasse o futuro como uma categoria que permitisse justificar as ações do passado. Neste sentido, mostrarei as formas e a relação entre o pensamento do autor em questão com a questão da disciplinarização da História.
\end{abstract}

Palavras-chave: Robert James Maddox. Previsão do Futuro. História. Bomba Atômica.

\section{Para citar este artigo:}

NETO, Mario Marcello. Uma filosofia do futuro? Robert James Maddox e a sua perspectiva sobre a bomba atômica. Revista Tempo e Argumento, Florianópolis, v. 9, n. 20, p. 308 - 332. jan./abr. 2017.

DOI: $10.5965 / 2175180309202017308$

http://dx.doi.org/10.5965/2175180309202017308 


\title{
A philosophy of the future? Robert James Maddox and his perspective about the atomic bomb
}

\begin{abstract}
What is the function and meaning of the "future" in history? This question can be answered in this article from the historiographical perspective of Robert James Maddox. This American Orthodox historian has devoted much of his academic life to studies on the atomic bomb and deconstructs the "myths" of those who contested the use of nuclear weapons by the United States. My argument is that Maddox operates in a sense trying to see a drive last American in front of a gift even more fragmented. The function that the future is replaced to exercise in his narrative is the justification. In this sense, one might think that the historiographical writing Robert Maddox and his attempt to prove (empirically and rhetorically) the necessity of the use of atomic bombs made him use the future as a category that would allow justify the actions of the past. In this sense, show the forms and the relationship between the thought of the author in question with the question of the history of disciplining is the task we have developed throughout this article.
\end{abstract}

Keywords: Robert Maddox. Predicting the Future. History. Atomic Bomb.

"O passado não reconhece seu lugar,

Está sempre presente."

(Mario Quintana) 


\section{Quem é Robert James Maddox?}

A historiografia estadunidense pode ser, de forma geral, composta por grupos muito heterogêneos. O universo acadêmico de produção historiográfica nos EUA possui uma dinâmica e composição que se diferencia dos modelos estabelecidos no Brasil. Embora um discurso contestador, em prol de causas consideradas à esquerda política, esteja presente na maioria dos departamentos de História dos EUA, como aponta Kammen (1997), existe uma pequena parcela, mas de significativa repercussão que se dedica a defender o status quo e a ordem vigente, bem como a construir embates e narrativas que não fragmentem o passado estadunidense e nem coloquem em xeque as narrativas já estabelecidas sobre a história desse país. Esses membros de uma corrente de pensamento fiel aos princípios da nação com relação à História, embora em menor quantidade, ganham notáveis espaços nas mídias e ambientes da sociedade civil, como o campo político e militar.

Com uma historiografia completamente heterogênea, formada por uma confluência de vertentes e posicionamentos políticos, nos EUA, é possível encontrar nos departamentos de História professores de extrema direita ou conservadores clássicos que relegam qualquer possibilidade de realizar uma outra leitura dos eventos do passado. Desta forma, o campo historiográfico estadunidense deve ser visto como um lugar imensamente disputado, no qual uma parcela significativa de historiadores profissionais entram em conflito sobre a possibilidade mais ética e "correta" de narrar o passado "glorioso da nação estadunidense". Um discurso em prol do objetivismo, uma defesa exacerbada da nação e um combate feroz aos "inimigos anti-americanistas" (MADDOX, 1995), são as finalidades maiores dessa historiografia estadunidense denominada por Jacoby (1990) de ortodoxa.

As semelhanças entre os ortodoxos e a tradicional historiografia do século XIX são paralelos constantes que devem ser traçados. O projeto de nação nos EUA, por mais que possa ter enfrentado resistências, é constantemente impulsionado por grupos que tentam formar uma coalisão interna e expandir seus valores para o mundo. Os ideais de democracia e liberdade são máximas que encontram espaço e reverberação na historiografia estadunidense no eixo dos ortodoxos. Robert James Maddox se situa 
exatamente neste grupo, advindo de uma historiografia que tem como objeto biografar grandes personalidades estadunidenses, como, por exemplo, senadores, deputados e diplomatas - vale ressaltar que esses biografados são, em maioria, homens, brancos e com uma vida pública na qual assumem o papel de pai de família exemplar: heterossexual e mantenedor do sustento da casa. Esta "tradição historiográfica” de origem diplomática, da qual Robert Maddox faz parte, ocupa um lugar importante dentro dos departamentos de história nos EUA, bem como sua reverberação nos setores públicos nos quais há a demanda por historiadores.

Um caso emblemático é a percepção da inserção desses historiadores de vertente ortodoxa nas esferas políticas, sejam elas estaduais, federais ou municipais. Samuel Eliot Morrison (1887-1976), Arthur Schlesinger Jr² (1917-2007), Robert Maddox (1932-), John Lewis Gaddis $^{3}$ (1941-), entre outros, fazem parte deste grupo, no qual todos já executaram tarefas em governos políticos - normalmente de republicanos - seja como conselheiro ou assessor histórico (ARMITAGE, 2014). Um caso mais emblemático torna-se quando estes historiadores de cunho ortodoxo, que pouco dialogam com seus pares de outras vertentes de pensamento - me refiro a um diálogo propositivo, não apenas de crítica e acusações -, assumem a posição de escreverem livros e/ou artigos em defesa de uma posição “correta” da história - principalmente da história dos EUA.

\footnotetext{
${ }^{1}$ Historiador e militar da marinha estadunidense, Morison executou funções historiográficas tão louvadas pelo governo estadunidense que acabou culminando na sua premiação, em 1964, pelo presidente Lyndon Johnson, com a medalha "Presidential Medal of Freedom", maior honra civil existente nos EUA. No prefácio de seu livro, "The Rising Sun in the Pacific", comenta que o mesmo surgiu a partir da autorização de Franklin Roosevelt para que acompanhasse a marinha estadunidense durante a Segunda Guerra Mundial, para que pudesse documentá-la e escrever sobre ela a partir da perspectiva dos EUA, principalmente, de uma versão militar da história.

${ }^{2}$ Renomado historiador, conselheiro e crítico social nos governos de Franklin Roosevelt e John Kennedy. Crítico ferrenho do multiculturalismo e defensor do liberalismo, Schelesinger Jr foi um articulador político não só intelectual, mas no exercício de papéis importantes nos governos democratas durante a Guerra Fria.

${ }^{3}$ Foi amigo pessoal e biógrafo do diplomata e cientista político George Kennan, um dos mais importantes e influentes acadêmicos na construção de um arcabouço intelectual e planejamento estratégico durante a Guerra Fria. Também tem estreita relação com o ex-presidente George W. Bush, a qual pode ser vista para além das fotos e vídeos de encontros entre ambos publicadas na internet, em colunas escritas por Gaddis em diversos jornais e revistas. Ver a reportagem de Mary Habeck (Professora de Estudos Estratégicos na John Hopkins University) que aborda os livros publicados sobre o " 11 de setembro" e a forma como trata sua relação com George W. Bush. Disponível em: < http://www.the-americaninterest.com/2005/09/01/reading-911> Acesso em: 24/02/2016.
} 
Robert James Maddox é um historiador ortodoxo estadunidense. Vinculado a uma vertente diplomática da História, sua formação acadêmica se deu a partir de biografias de oficiais e políticos estadunidenses, como é o caso de sua tese sobre o senador William E. Borah $^{4}$, que se transformou em livro em 1970. Posteriormente, provavelmente por necessidades pedagógicas (uma vez que Maddox inicia seu período como docente na Pennsylvania State University ainda na década de 1970) passa a dedicar seus estudos à Guerra Fria e seus conflitos.

Seu foco especial estava sobre quem haveria começado tal período e os fatores que levaram à eclosão de uma era tão instável, como a metade final do século XX. Para realizar estes estudos, Maddox recorreu ao evento-chave de compreensão do desfecho da Segunda Guerra Mundial: a bomba atômica. A partir de então, Robert Maddox publica diversos artigos e livros sobre essas temáticas, todos pautados em uma forte empiria e discurso retórico, que vê nas fontes o fato concretizado, a invariável verdade e as descreve. Neste sentido, Maddox exerce uma atividade acadêmica de cunho combativo, que tem seu principal alvo a New Left (a qual dedica um livro inteiro para desmentir suas “falácias” (MADDOX, 1973), e principalmente o economista político Gar Alperovitz (1965), autor do clássico: “Atomic Diplomacy: Hiroshima and Potsdam”, no qual cunha a tese de que a bomba atômica foi lançada para intimidar a URSS e não, como defende Maddox, para forçar o rendimento do Japão. As visões de passado, presente e futuro de Maddox são, em grande parte, uma resposta às formas de ver a temporalidade por seus “inimigos", entretanto, neste "campo de batalha intelectual” articular as relações com o tempo em prol de uma narrativa mais coerente com a sua ideologia é uma artimanha retórica desenvolvida pelo autor e que trataremos melhor a seguir.

Ainda nesta conjuntura, a Guerra do Vietnã (1955-1975) foi, certamente, um dos grandes limiares das discussões e das (re)visões sobre o papel dos EUA na história e da necessidade se (re)pensar a historiografia estadunidense e o questionamento do que causou a Guerra Fria e, por exemplo, a possibilidade concreta de extinção da humanidade através da bomba atômica. Neste contexto de questionamentos e dúvidas acerca da importância do papel dos EUA na Segunda Guerra Mundial (como o grande vencedor que derrotou a Alemanha Nazista e o famigerado império Japonês -, ou como a grande

\footnotetext{
${ }^{4}$ Sobre isso, ver Maddox (1970).
} 
internos, sobre a validade e a necessidade da Guerra do Vietnã. Ao avançar para perto dos 10 anos de duração da guerra, os questionamentos acerca da sua validade, dos seus altos investimentos e dos seus escusos objetivos geraram um debate tenso, no qual a pergunta central era: “Alguém começou a Guerra Fria?”" (STELL, 1971 - tradução minha).

Neste sentido, Robert Maddox se posiciona, assume a responsabilidade, implícita, mas evidente, de ocupar a posição deixada por Samuel Eliot Morrison (que falece em 1975, mas que desde a década de 1960 estava com a saúde bem debilitada). Inicia, desde o início da década de 1970, uma série de livros e artigos tentando desconstruir os "mitos" e questionando o papel dos "revisionistas", principalmente da New Left. Seu ponto de argumentação inicial era a Segunda Guerra Mundial e, segundo ele, as falácias acerca do desfecho da guerra proferidas pela New Left. Entre as principais acusações está o papel ocupado pelos EUA no fim da guerra, seja como protagonista que derrotou o eixo, ou um importante aliado, mas que acabou ofuscado pelo furor do exército soviético, como argumentavam renomados nomes da historiografia da New Left estadunidense, como, por exemplo, William Appleman Williams.

Logo, seus argumentos rumaram para uma questão crucial de interpretação do papel dos Estados Unidos na Segunda Guerra Mundial: o uso da bomba atômica. Para ocupar-se desta questão, Maddox $(1973,1995$, 2007) dedicou-se, quase que exclusivamente, a essa questão ao longo de sua carreira acadêmica. Dedicado a comprovar as suas teses sobre a necessidade do uso das armas nucleares para vencer a guerra, entre outros tópicos, isso me permite inferir diversos elementos a partir da sua concepção de história com relação a uma possível "filosofia do futuro", implicitamente proposta por Robert Maddox. Para chegar a esta compreensão de futuro, é preciso, no entanto, compreender o que Maddox entende com relação ao tempo histórico, bem como o papel do presente e do passado, para que com isso seja possível entender a sua "filosofia do futuro".

\footnotetext{
5 "Did Anyone Start the Cold War?" (texto original).
} 


\section{Presente: O momento da disputa}

O presente como disputa é uma arma apontada para nós mesmos. Essa frase anterior pode, claramente, definir a visão de Maddox acerca do papel do presente para o historiador - veja, que não se refere ao papel do presente na história. A grande contradição da vertente ortodoxa de considerar o presente como um espaço de disputa é que a mesma apresenta como ideia básica a defesa da objetividade e a pretensão à verdade, sem espaço para distorções ou para convivência de diversos discursos históricos ao mesmo tempo.

Neste sentido, o presente ocupa um espaço central na vida do historiador. É o momento em que ele deve se posicionar e tomar partido, lutar para que o passado não seja admoestado, nem deturpado. O presente é um momento, a partir desta percepção, de constante luta, de confronto, para que o passado possa se manter estável e em paz, dentro da normalidade que lhe é rotineira - ou que, ao menos, deveria ser. Pensar o papel do presente no historiador não implica, necessariamente, em repensar o papel do presente na História.

Para Robert Maddox, a história não se pode deixar levar pela confluência de ideologias e ideias que estão em voga no seu momento de escrita. Acreditando ele, estar fora do emblemático mundo da Guerra Fria, pautava que a história deveria ser imparcial, que não se tornasse revisionista e apologética de ideologias - se referindo ao marxismo e, muito menos, construíssem "mitos” com relação à história nacional.

Os termos "mito" e "revisionismo", aqui, adquirem um caráter ressignificante e importante para minha argumentação. Para Maddox (1973), mitos são as narrativas historiográficas que questionam a história oficial estadunidense, bem como apresentam outras interpretações para as mesmas fontes. Essa argumentação é pautada na ideia de que existe apenas uma leitura possível do passado, uma leitura correta e imparcial do mesmo. Toda e qualquer outra leitura do passado será pautada pelo controle ideológico, pelo uso do passado por historiadores de má fé, em prol da defesa de sua ideologia. Este cenário construído, embora se assemelhe com a historiografia tradicional do século XIX, muito bem descrita por White (2010), possui uma premissa básica que o diferencia: a 
fragmentação da ideia de nação é muito mais evidente nos EUA da metade final do século XX do que na Europa do século XIX.

Pensar a luta pelos direitos civis, a luta das mulheres, gays e negros, bem como o movimento pacifista, antiguerra e outros, tornam a história oficial dos EUA uma contradição neste contexto (WEST, 1994), ao mesmo tempo em que é desnecessária e antiquada, ela deveria ser reforçada para defender os ideais nacionais. Essa foi a posição tomada por Maddox: defender a nação dos inimigos. Acreditava que seus inimigos eram ideológicos, e algo externo que queria interferir na estabilidade de sua nação, portanto, a sua leitura do presente não permitiu perceber o abalamento do ideal de nação (composta por homens brancos e ricos). A demanda agora era por uma nação plural, multiétnica, pautada pela imigração, entre outras questões, que Maddox não conseguiu perceber. Neste sentido, as:

Metáforas fortes da sociedade foram suplantadas pelos mais fracos. Coletividades imaginadas encolheram; noções de estrutura e poder dizimadas. Visto por seus atos da mente, o último quartel do século foi uma era de desagregação, uma grande idade da fratura. ${ }^{6}$ (RODGERS, 2011, p. 3)

Com relação ao termo "revisionismo", fica evidente o posicionamento do autor com relação ao campo ocupado por ele. O termo é utilizado para definir toda e qualquer narrativa que questione a versão oficial da história estadunidense. Revisionistas são todos aqueles que questionam o status quo, o papel protagonista dos EUA e sua reputação. Sendo assim, segundo Robert Maddox:

Tem sido uma fonte de diversão e consternação testemunhar os gritos de indignação justos dentro da profissão histórica sobre casos de plágio que foram revelados durante os últimos anos. Nas palavras roubadas de outra pessoa é indefensável, é claro, mas são comparativamente pequenas batatas porque os autores envolvidos não estavam tentando enganar os seus leitores sobre o que realmente aconteceu. Alterando as fontes para fornecer suporte para interpretações pré-fabricadas é uma ofensa muito maior, ainda que os seus esforços para expor as práticas

\footnotetext{
6 "Strong metaphors of society were supplanted by weaker ones. Imagined collectivities shrank; notions of structure and power thinned out. Viewed by its acts of mind, the last quarter of the century was an era of disaggregation, a great age of fracture" (texto original).
} 
profissionais dos revisionistas sobre Hiroshima tenderam a ser menosprezados como mera picuinha ou 'verificação de nota'.' (MADDOX, 2007, p. 22-23 - tradução minha)

Neste caso, a síndrome do "Capitão América" também se enquadra nesta conjuntura. Tal síndrome é composta pelo ideal de que a política externa dos EUA é baseada em um escudo, no qual os EUA jamais atacam, sempre se defendem. Assim como o escudo utilizado pelo personagem das histórias em quadrinhos, os EUA sempre se mantiveram em uma defensiva diplomática - ao menos no discurso - e sempre justificam suas atitudes a partir de um ataque anterior por parte de seus inimigos. No entanto, a bomba atômica é justificada pela existência do ataque a Pearl Harbor, e qualquer tentativa de interpretar este evento de maneira diferente será vista, pela vertente ortodoxa, como um ato revisionista.

\section{A disciplinarização da História: o intocável e glorioso passado}

O passado não é uma compreensão dada. Seu sentido e sua função social são questões complexas e cambiantes. No entanto, neste momento, tentarei demonstrar como a construção do saber disciplinado sobre o passado, o que se convencionou chamar de "História", permitiu construir argumentos e uma forma de pensar que não só legitima os argumentos de Robert Maddox, como permite que o mesmo acuse e argumente contra todos aqueles que não concordem com seu ponto de vista, calcado em uma crítica historicista, fundada nos “princípios básicos da disciplinarização da 'História”, que segundo Peter Novick, ao analisar o discurso sobre a objetividade na historiografia estadunidense, se caracteriza por:

\footnotetext{
7 "It has been a source of both amusement and dismay to witness the cries of righteous indignation within the historical profession over instances of plagiarism that have been revealed during the past few years. Pilfering another person's words is indefensible, of course, but is comparatively small potatoes because the authors involved were not trying to mislead their readers as to what actually happened. Altering the sources to provide support for prefabricated interpretations is a far greater offense, yet efforts to expose the unprofessional practices of Hiroshima revisionists have tended to be disparaged as mere nitpicking or 'footnote checking."' (texto original).
} 
[...] inclui um compromisso com a realidade do passado, e a verdade como correspondente dessa realidade; uma separação nítida entre sujeito e objeto, entre fato e valor, e, sobretudo, entre história e ficção. Os fatos históricos são vistos como antes e independente de interpretação: o valor de uma interpretação é julgado por quão bem ela explica os fatos; se contrariada pelos fatos, deve ser abandonada. A verdade é única, não uma perspectiva. Sejam quais forem os padrões existentes na história eles são "encontrados", não "feitos". Apesar de sucessivas gerações de historiadores poderem, como suas perspectivas mudam, atribuir diferentes significados para os eventos do passado, o significado desses eventos torna-se imutável. O papel do historiador objetivista é de um neutro, ou desinteressado, juiz; ele nunca deve degenerar para um advogado ou, pior ainda, propagandista. Conclusões são esperadas para exibir as qualidades do padrão judicial de equilíbrio e imparcialidade. Tal como acontece com o sistema judiciário, essas qualidades são garantidas pelo isolamento profissional da pressão social ou influência política, e pelo historiador evitando partidarismos ou tendências - não tendo qualquer investimento em chegar a uma conclusão em vez de outra. Objetividade é considerada um grave risco quando a história é escrita para fins utilitários. Um corolário de tudo isto é que os historiadores, como historiadores, devem purgar-se de lealdades externas: lealdade primária do historiador é "o objetivo verdade histórica", e colegas de profissão que compartilharam um compromisso de cooperação, os esforços cumulativos para avançar em direção a esse objetivo. ${ }^{8}$ (NOVICK, 2005, p. 1-2 - tradução minha)

Um historiador objetivista, como descreve o excerto acima, opera dentro das características consideradas o fundamento da disciplina histórica. Sair desta prática é, contudo, um desvio e um erro. A ortodoxia desses historiadores se estabelece justamente na impossibilidade de alterar os modos do fazer historiográfico, alegando que isso tornaria o mesmo uma ficção e, portanto, algo sem valor científico ou acadêmico.

8 " [...] include a commitment to the reality of the past, and to truth as correspondence to that reality; a sharp separation between knower and known, between fact and value, and, above all, between history and fiction. Historical facts are seen as prior to and independent of interpretation: the value of an interpretation is judged by how well it accounts for the facts; if contradicted by the facts, it must be abandoned. Truth is one, not perspectival. Whatever patterns exist in history are "found," not "made." Though successive generations of historians might, as their perspectives shifted, attribute different significance to events in the past, the meaning of those events was unchanging. The objective historian's role is that of a neutral, or disinterested, judge; it must never degenerate into that of advocate or, even worse, propagandist. The historian's conclusions are expected to display the standard judicial qualities of balance and evenhandedness. As with the judiciary, these qualities are guarded by the insulation of the historical profession from social pressure or political influence, and by the individual historian avoiding partisanship or bias-not having any investment in arriving at one conclusion rather than another. Objectivity is held to be at grave risk when history is written for utilitarian purposes. One corollary of all of this is that historians, as historians, must purge themselves of external loyalties: the historian's primary allegiance is to "the objective historical truth," and to professional colleagues who share a commitment to cooperative, cumulative efforts to advance toward that goal" (texto original). 
Para tanto, na tentativa de construir um argumento que fundamente a construção das matrizes disciplinares da História, utilizarei para esta reflexão o argumento desenvolvido por Hayden White (2014), naquilo que ele - a partir da proposição feita por Michael Oaekshott - chamou de "passado prático" e "passado histórico". Para White (2014), as formas como os "historiadores profissionais" utilizam o passado é diferenciada da forma que as pessoas, em seu dia-a-dia, o utilizam. A função, a forma e a narrativa construída em relação a este passado pelos historiadores possuem características únicas que se devem ao processo de disciplinarização da História no século XIX e a consequente metodização no século XX.

No seu último livro, "The Pratical Past”, Hayden White (2014) define passado histórico da seguinte maneira:

O passado histórico é uma construção motivada teoricamente, existindo apenas nos livros e artigos publicados por historiadores profissionais; ele é construído como um fim em si mesmo, possui pouco ou nenhum valor para compreender ou explicar o presente, e não fornece orientações para agir no presente ou prever o futuro ${ }^{9}$. (WHITE, 2014, p. 9 - tradução minha)

O século XIX e o processo de criação da ciência histórica, ou da histologia - para utilizar um termo mais "científico" - permitiu que as formas de se pensar o passado fossem regradas a partir de métodos e estratégias que permitiriam uma visão pura do mesmo, uma compreensão nítida do que havia acontecido e o historiador deveria assumir um papel de total imparcialidade. Esse discurso, muito forte no século XIX, que pode ser percebido nas obras de Leopold Von Ranke - o seu expoente máximo -, se tornou obsoleto no século XX, porém não foi esquecido.

No século XX, o discurso da disciplinarização não deixou de existir, mas tomou outras formas. Se, no século anterior, a separação radical entre história e literatura, entre ficção e realidade, foram topos extremamente importantes, posteriormente, desde o fim

\footnotetext{
9 "The historical past is a theoretically motivated construction, existing only in the books and articles published by professional historians; it is constructed as an end in itself, possesses little or no value for understanding or explaining the present, and provides no guidelines for acting in the present or foreseeing the future." (texto original).
} 
imparcialidade, da consideração das fontes como portadoras da verdade até outros modos de problematizar a relação com o passado. No entanto, segundo White (2014), um dos principais elementos disciplinadores permaneceram: a ideia de que o "método histórico" é o responsável por buscar a verdade do passado - ou algo muito próximo disso. Desconsiderar os fatores linguísticos, representacionais, entre outros - que só surgiram a partir da Virada Linguística - tornam o ofício do historiador ${ }^{11}$ algo fechado em si mesmo. Assim, constrói-se o "passado histórico", deslocado de sentido, que tem uma relação apenas com outros passados históricos, mas não com a vida "real". Sua serventia está no processo de discussão e estabelecimento de sentido a um passado existente, porém sem ser utilizado para nenhum fim além de escrever artigos, teses e livros.

Esse "passado histórico" tem como seu principal aliado um elemento crucial no desenvolvimento desta ideia: o apelo nacionalista. Como comentei anteriormente, a História foi construída no século XIX com características muito marcantes. No entanto, seu sentido e seu uso eram justamente para corroborar, reforçar e propagar o Estadonação. Uma História que tinha por função estabelecer identidades nacionais, exaltar os heróis de um dado país e suas principais conquistas. Essa historiografia, principalmente a partir do século XX começa a entrar em crise ${ }^{12}$, a história como um braço da nação não tem mais sentido. O próprio sentimento nacionalista já não é mais o mesmo, a relação da comunidade imaginada - como argumenta Benedict Anderson (2008) - boa parte se esvai após a Segunda Guerra Mundial.

\footnotetext{
${ }^{10}$ Historiador estadunidense (1861-1932), responsável pela famosa Frontier Tesis, que coloca em pauta a narrativa da conquista do oeste estadunidense, desde o fim do século XIX propunha uma história problema, uma metodologia mais rígida e uma ampliação no conceito de fontes. Sobre isso ver: (TURNER, 2005).

${ }^{11}$ Quando me refiro a este termo, faço alusão à ideia de ofício: um saber especializado conduzido por um especialista que domina certas técnicas e o manuseio de determinados materiais.

12 A chamada "Crise da História", diagnosticada no fim da década de 1960 - principalmente após a difusão dos textos de Derrida e Deluze no mundo -, gerou não só um grande desconforto para muitos historiadores, como questionamentos efusivos acerca do ofício do historiador, da sua prática e sua serventia social.
} 
A nação não ocupa mais um lugar a qual os historiadores ainda precisam realizar sua defesa. Ela, por mais questionada que esteja, ocupa um lugar já definido, não necessita mais de defesa, de exaltação ou argumentos que legitimem a sua existência. Seus principais inimigos foram aniquilados: a nobreza feudal (contrária a um desenvolvimento burguês) e os utópicos (marxistas, anarquistas, positivistas e outros que ameaçavam o capitalismo com a possibilidade de existência de um estágio civilizacional superior ao existente, em que as relações sociais não seriam pautadas no capital financeiro).

Essa historiografia do século XIX, embora, aparentemente, superada, vencida, deixou rastros significativos na produção historiográfica recente. Além do discurso da nação, que se superado, deixou a historiografia sem sentido para as pessoas. Afinal, se não for para construir uma identidade nacional, para que serve a história? Qual o sentido das pesquisas historiográficas que fizemos hoje? Essas perguntas não poderão ser respondidas facilmente por nenhum historiador. No entanto, essa percepção da crise, da falta de sentido na produção historiográfica, permitiu existir um distanciamento maior entre a produção do historiador e a demanda social. Tal demanda, como argumenta Huyssen (2007), foi preenchida pela memória (em excesso, em tempos atuais) e pela super-patrimonialização. Na falta de uma historiografia da nação, constrói-se uma memória nacional.

Robert Maddox encontra-se justamente neste entremeio. Um historiador do século $X X$ - tendo escrito praticamente todos os seus textos neste período - que, como um ferrenho ortodoxo, defende as posições historicistas fundadas no século anterior, principalmente no que versa sobre suas posições em relação à História e ao ofício do historiador. A defesa de uma história neutra, que "busca a verdade", sem "influências ideológicas" e com total compromisso às fontes é algo marcante no fazer historiográfico de Maddox.

Essa reflexão teórica e metodológica sobre a história não é algo feito conscientemente por Maddox, mas, por exemplo, ao acusar os "revisionistas" de construírem "mitos" sobre a bomba atômica, o autor acaba realizando uma teorização acerca do que considera como legitimo e correto no trabalho do historiador. Focando 
imensamente em pressupostos historicistas, o autor em questão tem como proposta central um "resgate" do passado a partir da descrição das fontes pelos historiadores, sem se preocupar com as possibilidades múltiplas de representação, análise e narrativas da mesma. Em seus argumentos (e nas fontes por ele utilizadas) não há espaço para considerar fontes além dos documentos oficiais. Uma diversificação maior das fontes e das abordagens históricas (incluem-se aqui até disposições teóricas mais complexas), não fazem parte do escopo do que "deveria ser estudado pelos historiadores”. Tal percepção pode ser vista na introdução de seu último livro, "Hiroshima in History", na qual, ao final do texto, faz uma séria crítica aos "revisionistas" e deixa claro que o fazer historiográfico não pode ser utilizado para comprovar teses sem fundamentos nas fontes. Ele diz que:

Os ensaios no presente volume revelam que revisionistas sobre Hiroshima construíram uma estrutura em ruínas fundada na areia. Se o registro histórico suporta as suas teses, deve-se perguntar, por que eles são obrigados a recorrer a procedimentos duvidosos, como cortar documentos para alterar seu significado ou depender de fontes desacreditadas como o USSBS? Um problema relacionado é por que suas obras continuam a receber atenção muito favorável nos círculos acadêmicos? A resposta a ambas as perguntas parece ser que as agendas políticas têm superado os compromissos de bolsa de estudos. Alguém pode ainda descobrir evidências que validem a posição revisionista. Que ninguém foi capaz de fazê-lo durante os mais de sessenta anos desde Hiroshima torna esta perspectiva aparentemente burra. ${ }^{13}$ (MADDOX, 2007, p. 6)

Ao trazer para o centro de sua proposta a ideia de que o passado está lá, nas fontes, e precisa apenas ser transcrito, Maddox deixa um espaço cognitivo que me permite inferir que, em sua proposição acerca do passado, a construção de uma narrativa nada mais é que uma formalidade, uma simples - e imparcial - transcrição. Ao questionar os "procedimentos" e os "cortes de documentos", o autor ignora que tal procedimento é parte imprescindível do trabalho do historiador. Neste sentido, a fase documental é

13 "The essays in the present volume reveal that Hiroshima revisionists have constructed a ramshackle structure founded on sand. If the historical record supports their theses, one must ask, why are they compelled to resort to dubious procedures such as scissoring documents to change their meaning or relying on discredited sources such as the USSBS? A related issue is why do their works continue to receive so much favorable attention in academic circles? The answer to both questions appears to be that political agendas have trumped commitments to scholarship. Someone may yet discover evidence that validates the revisionist position. That no one has been able to do so during the more than sixty years since Hiroshima makes this prospect appear dim" (texto original). 
centrada na seleção de fontes, organização e narração, para isso, é necessário selecionar partes a serem destacadas e outras, por obviedade e questões narrativas serão ignoradas ou não mencionadas. O descontentamento de Maddox se dá não por questões metodológicas, mas por questões éticas e políticas. Para o autor supracitado, o problema reside no fato de que as citações mencionadas pelos "revisionistas" questionam as narrativas oficiais dos EUA; o contrário não é um problema para Maddox.

Como diz Kammen (1980), essa historiografia pautada nesses modelos historicistas, do século XIX, embora em menor número, ainda impera nos dias atuais. Maddox tem muitos colegas que compactuam com suas ideias e continuam a produzir sobre a temática da bomba atômica no mesmo estilo ${ }^{14}$, mesmo após a sua aposentadoria.

O papel do passado nesta concepção do ofício do historiador - associando a ideia de que a História (disciplina) é um trabalho que só pode ser exercido por seres muito bem treinados e qualificados, dando um caráter de um labor, algo a ser construído por habilidosas mãos a partir de ferramentas típicas que exigem um saber disciplinado adotado por Maddox exerce um caráter importante que reivindica claramente aquilo que Hayden White (1987) problematizou em seu emblemático livro: The content of the form, no qual o atrelamento entre História e nação faz parte de um discurso maior que tenta suplantar, de vez, as filosofias da história que tenham um mote utópico e, por conseguinte, que deslegitimem um conhecimento pragmático do passado. Para ele:

Em uma época caracterizada por conflitos entre representantes de uma série de posições políticas, cada um dos quais trouxe a participação de uma "filosofia da história" ou narrativa mestra do processo histórico, com base no que suas reivindicações de "realismo" foram em parte autorizadas, conseguiu eminentemente bom senso para constituir uma disciplina especificamente histórica. A finalidade de como uma disciplina poderia simplesmente determinar os "fatos da história", pelos quais avalia a objetividade, veracidade e realismo das filosofias da história que autorizaram os diferentes programas políticos. Sob os auspícios da filosofia da história, os programas de reconstrução social e política compartilham uma ideologia com visões utópicas do homem, da cultura e da sociedade. Esta vinculação justificada de ambas e fez um estudo da história, considerada como uma recuperação dos fatos do passado, uma aspiração social, ao mesmo tempo epistemologicamente necessária e politicamente relevante. Para analisar os elementos desta vinculação, a crítica epistemológica procedeu, opondo um método histórico

\footnotetext{
${ }^{14}$ Sobre isso ver: Wilson Miscamble (2011), Sadao Asada (1998), entre outros.
} 
devidamente disciplinado concebido como empírico a uma filosofia da história concebida como inerentemente metafísica. O aspecto político deste esforço analítico consistiu na oposição de uma consciência histórica devidamente disciplinada com o pensamento utópico em todas as suas formas (religiosas, sociais e, sobretudo, política). A combinação destes dois aspectos da disciplinarização da história teve o efeito de permitir que o tipo de conhecimento histórico produzido por historiadores profissionais para servir como padrão de realismo no pensamento e ação política em geral. ${ }^{15}$ (WHITE, 1987, p. 61).

O passado, nesta perspectiva, exerce uma clara função de exaltação da nação, de justificar o sentimento nacional, exaltar seus heróis e feitos, como afirma Dirk Moses (2005). Mesmo ante a críticas e à dissolução de sentimentos nacionais e com a desnecessidade da defesa da nação por uma disciplina como a História ${ }^{16}$, a vertente ortodoxa, a qual Maddox pertence, não consegue conceber que o passado seja algo fragmentado, em uma grande convulsão de acontecimentos, um verdadeiro conflito de narrativas dissonantes, conflitantes e em eterna disputa.

A união e a paz da nação são uma dádiva que pertence ao passado. Um passado de paz e glória, sem sangue e luta. Esse mesmo passado idealizado pelos ortodoxos é uma nítida resposta ao conflituoso presente. Ver o passado como algo sem conflito ${ }^{17}$, em que as rupturas não fazem parte do contexto é dizer que a continuidade, a construção da

15 "In an age characterized by conflicts between representatives of a host of political positions, each of which came attended by a "philosophy of history" or master narrative of the historical process, on the basis of which their claims to "realism" were in part authorized, it made eminently good sense to constitute a specifically historical discipline. The purpose of such a discipline would be simply to determine the "facts" of history, by which to assess the objectivity, veridicality, and realism of the philosophies of history that authorized the different political programs. Under the auspices of the philosophy of history, programs of social and political reconstruction shared an ideology with utopian visions of man, culture, and society. This linkage justified both and made a study of history, considered as a recovery of the facts of the past, a social desideratum at once epistemologically necessary and politically relevant. To analyze the elements of this linkage, the epistemological criticism proceeded by opposing a properly disciplined historical method conceived as empirical to a philosophy of history conceived as inherently metaphysical. The political aspect of this analytical effort consisted in opposing a properly disciplined historical consciousness to utopian thinking in all its forms (religious, social, and above all political). The combination of these two aspects of history's disciplinization had the effect of permitting the kind of historical knowledge produced by professional historians to serve as the standard of realism in political thought and action in general" (texto original).

${ }^{16}$ Neste texto, quando eu usar o termo "História", com a primeira letra em maiúsculo, estaria me referindo à disciplina de "História", construída, sobretudo, no século XIX.

${ }^{17}$ Os conflitos aos quais me refiro são os conflitos internos, as dissonâncias entre os grupos pertencentes à nação. No caso dos Estados Unidos, as questões dos índios, dos negros, das mulheres, dos gays e de outros grupos que disputam direitos, narrativas e espaço na sociedade e na História, podem ser vistas como uma forma conflituosa do passado e não como um período consensual, de paz, de construção e manutenção da ordem nacional. 
coesão são as premissas básicas para compreender a sociedade. Tudo isso em meio a um presente de insegurança, de ruptura, de críticas tanto ao papel da nação estadunidense, quanto ao papel do império estadunidense, a crítica aos valores "democráticos" e de "liberdade"18 que, entre outras coisas, levaram a Guerra do Vietnã.

Ao questionar quem iniciou a Guerra Fria, Robert Maddox aponta suas críticas para os que problematizam as práticas arbitrárias dos governos estadunidenses: como o uso da bomba atômica, os inúmeros conflitos gerados a partir de intervenções militares no exterior, o financiamento e apoio a ditaduras que torturaram e mataram inúmeras pessoas em diversos lugares do globo, entre outras questões discutíveis e controversas. Maddox deixa evidente nos seus textos que essas narrativas desestabilizam a sua ideia de um passado idealizado, uno e em paz, tornando-o passível de discussões, problematizações e interpretações outras. Neste sentido, para o autor em questão, não é possível conceber que a linearidade do passado é apenas uma interpretação, mas não a única possível, tornando as narrativas oficiais sobre essa linearidade e unicidade desse passado totalmente desestabilizadas. Conforme argumenta Dominick Lacapra ${ }^{19}$ sobre os discursos de unidade e coesão do passado:

Podemos muito bem perguntar: como é possível que tenham existido relatos totalmente contestadores acerca dos marcos históricos tão diversos como Plymouth Rock, Santa Fé e o Álamo? Qual é o ponto de vista dos índios norte-americanos com relação à fronteira e o destino manifesto? Que papel ocupam a Guerra Civil e as narrativas que contam? Pode-se dizer que nunca houve uma única narrativa, e a maioria dos norte-americanos nunca aceitaram uma única história sobre seu passado. $^{20}$ (LACAPRA, 2005, p.102 - tradução minha).

\footnotetext{
${ }^{18}$ Kiernan (2009) argumenta que a nação estadunidense é construída em cima de dois pilares: a democracia e a liberdade. Esses dois conceitos mudam de acepção ao longo do tempo, mas a máxima defendida é a ideia de que a democracia e a liberdade não devem ser premissas básicas apenas nos EUA, mas no mundo. Segundo o autor, essas seriam as justificativas fundacionais para as intervenções internacionais nos Estados Unidos.

${ }^{19}$ Aqui o autor se refere ao discurso acusatório que os historiadores adeptos da "virada linguística" são alvo, ao acusar tais historiadores de serem os responsáveis pela fragmentação na História, projetando um cenário do passado nos quais o discurso histórico era uno e sem disputas, algo facilmente comprovável que não.

20 "Bien podríamos preguntar: ¿cómo es posible que hayan existido relatos totalmente contestes acerca de hitos históricos tan diversos como Plymouth Rock, Santa Fe y el Álamo?' ¿Qué hay del punto de vista de los indígenas norteamericanos con respecto a la frontera y el destino manifiesto? ¿Qué lugar ocupan la Guerra Civil y las narrativas que la relatan? Se podría decir que nunca existió una narrativa única, y que la mayoría de los norte-americanos jamás aceptaron un relato único acerca de su pasado" (texto original).
} 
O passado como glória é um princípio que dá a tônica para compreender não só o modelo historiográfico ortodoxo, mas também para compreender a fragmentação dos EUA no período após o Macarthismo ${ }^{21}$ e durante a Guerra do Vietnã, contextos nos quais Robert Maddox está situado.

\section{(Por) Uma filosofia do futuro?}

Na parte final deste texto, me dedicarei a falar daquilo que estou chamando de uma "filosofia do futuro" em Robert James Maddox. Tal concepção não é uma proposição do autor, mas sim uma análise minha a partir de determinada prática historiográfica do autor. Esta análise é pautada em uma ideia de futuro aliada a uma prática historiográfica.

Neste sentido, o termo "filosofia do futuro" se torna mais adequado do que uma “abordagem do futuro", pois existe uma concepção da função que o futuro exerce e que ele deveria exercer e, a partir disto, exerce uma forma de fazer História em que o futuro ocupa uma posição central, como o articulador das justificativas para as ações historiográficas do presente e do passado. Diversos historiadores lidaram de variadas formas com o futuro e até mesmo com a projeção de cenários futuros, como aponta Staley (2002); no entanto, o que Maddox faz torna-se diferenciado pela sua realocação de sentido e proposição de uma nova organização da função do futuro na História, embora a narrativa sobre tal questão continue exatamente a mesma: factual, objetiva e, no caso do autor, ácida e acusativa.

Diferentemente de uma filosofia do futuro utópica, na qual pensam o futuro como algo melhor, advindo de um progresso constante - típico do contexto do século XIX, segundo Koselleck (2006), Maddox pensa que ações são tomadas não apenas em nome de um futuro melhor, mas para impedir um futuro pior. Embora sejam acepções semelhantes, tornam-se coisas bem diferentes. Enquanto pensar um futuro melhor implica em uma ideia de progresso, de um processo superior civilizacional; pensar em

\footnotetext{
${ }^{21}$ Foi uma prática política adotada nos EUA por volta dos anos de 1950 até 1954, inspirada nos discursos sectários e persecutórios aos comunistas do senador Joseph McCarthy. Neste período, a perseguição, prisão e censura a tudo e todos que poderiam ser considerados comunistas deu-se em larga escala.
} 
evitar um futuro pior implica que ao existir uma previsão de futuro, se possa evitar que ela seja pior que a existente. Neste sentido, é uma metacrítica, ou seja, ou revisão da visão de futuro.

Tal formulação avança, naquilo que Feuerbach (1986) chamou de "Princípios da filosofia do futuro", pois permite pensar que a visão existente de futuro pode ser ainda pior caso algo não seja feito. No entanto, tal concepção de futuro - praticamente inexistente no levantamento feito por Minois (2000) sobre as formas de lidar com o futuro -, quando parte de um historiador, tem que ter alguma relação plausível com o passado, ou seu uso. Esta relação vai se dar justamente no uso do futuro como justificativa. Se grande parte da historiografia e de filósofos da história pensavam que as justificações para ações a serem tomadas estaria no passado, ou, no máximo, no presente.

Maddox inova ao propor que as justificativas para as ações tanto do historiador, quando dos homens ${ }^{22}$ históricos são tomadas a partir da percepção de qual futuro pode ser evitado. Neste sentido, admite-se que não se sabe qual futuro teremos, mas sabe-se qual futuro não queremos ter. Diferentemente daquilo que Liakos (2007) descreve sobre as utopias, em que se pensa exatamente no futuro que se quer ter, mas não se sabe exatamente o processo para chegar lá.

Essa diferenciação que evidencio no fazer historiográfico de Maddox se caracteriza por algo de ordem prática: a necessidade de justificar o uso da bomba atômica para além de argumentos empiristas e factuais. Para isso, a prática historiográfica realizada pelo autor em questão para acionar sua filosofia do futuro foi aderir a uma história contrafactual pautada em fontes. Pensar em uma narrativa sobre uma possibilidade do passado, relacionando-a com as piores possibilidades do futuro imaginado pelos partícipes daquela contemporaneidade. Ou seja, seria aquilo que Koselleck (2006) chamou de "futuro passado", só que agora, com o intuito de evitar um futuro pior, estudando as possiblidades piores $^{23}$ de existência desse futuro em um

\footnotetext{
${ }^{22}$ Não esquecendo que, para o autor, a história é um gênero masculino, feito exclusivamente por homens, normalmente brancos, heterossexuais e políticos ou militares.

${ }^{23}$ Obviamente que o termo "pior", aqui, é um conceito moral, tomado por Maddox e que só pode ser compreendido como algo pior àquilo que ele projetou como melhor para a conjuntura analisada.
} 
determinado momento do passado. Para isso, Maddox recorre a fontes oficiais que permitam a ele pensar em elementos contrafactuais que contrariam as teses de seus críticos.

O ano de 1995, para estudiosos da bomba atômica, foi o ano-chave para compreender não só as possíveis interpretações historiográficas do mesmo, mas para perceber os usos do passado sobre o mesmo e as formas pelas quais se constituem e se estabelecem relações para com um passado traumático e difícil de ser narrado. Neste ano, Robert Maddox organiza seu último livro: "Hiroshima in History: The Myths of Revisionism", no qual conta com artigo de diversos historiadores de vertente ortodoxa, inclusive o japonês Sadao Asada, que acompanha o discurso ortodoxo dos estadunidenses. Neste livro, Maddox condensa o trabalho de uma carreira toda para sustentar a tese de uma nação gloriosa do passado, de um presente de luta para manter a ordem desse passado, e de pensar que as ações são tomadas para que o futuro seja "menos pior" do que poderia ser.

Em outras palavras, à guisa de exemplo, isso significa dizer que pensar em possibilidades "menos piores" do futuro, significa pensar que em uma invasão estadunidense por terra ao Japão seria a única saída para vitória na Segunda Guerra Mundial - caso a bomba atômica não fosse utilizada -; no entanto, se essa invasão de tropas dos EUA acontecesse, morreriam mais soldados (homens de bem e que lutavam pela democracia contra um império autoritário e despótico) do que pessoas que morreram em virtude da bomba atômica. Para construir tal argumento, Maddox não se pautou apenas em um argumento fruto de uma erudição ou uma percepção de historiador, ele argumenta estar calcado em fontes, baseado em projeções "reais" sobre essa possibilidade clara de um "genocídio" estadunidense e japonês, como argumenta na introdução de seu último livro, dizendo que:

Aqueles que defendem a alegação de que a decisão que pôs fim a uma guerra sangrenta que se tornaria muito mais sangrenta tinha provado o necessário, a planejada invasão das ilhas japonesas. Embora a principal preocupação fosse de salvar vidas americanas, de acordo com este ponto de vista, milhões de japoneses também foram poupados dos efeitos 
catastróficos de uma invasão conjunta em 24 horas de um bombardeio convencional, bombardeio naval e um bloqueio. ${ }^{24}$ (MADDOX, 2007, p. 1)

Utilizando o “método histórico" (de acordo com princípios ortodoxos), o autor pauta-se por dados obtidos a partir das baixas dos soldados estadunidenses nas invasões ao Eixo na Europa e a dados da potencialidade bélica do Japão em meados de 1945. Interessante pensar que a filosofia do futuro que propõe uma forma de pensar as formas "menos piores" de futuro no passado, se pautam em dados concretos do passado, já realizados e estimados. Para além da discussão possível sobre interpretação desses dados, é preciso ter em mente que a existência desses dados depois dos eventos consumados, gera um problema de característica ontológica e existencial, na qual compreender as possibilidades de futuro no passado só se torna possível depois que esse futuro já não existiu.

Essa tendência contrafactual não é uma novidade nos EUA. Tais métodos são muito defendidos por historiadores como Ferguson (2000) e Bunzl (2004), tem como características centrais pensar as possibilidades múltiplas do passado. Utilizam-se de fontes para pautar seus estudos, mas, sobretudo, pautam-se em análises conjecturais feitas a partir do conhecimento dos agentes envolvidos e das suas possibilidades de ação.

Esta forma de narrar a história, para esses historiadores, trata-se, apenas, de um exercício cognitivo e reflexivo acerca das possibilidades do passado. Neste sentido, não só a representação do mesmo e suas diversas possiblidades e aspectos existentes, mas também as outras formas e possiblidades de passados possíveis, mas que não ocorreram. Pensar a história a partir da máxima "e se tal coisa não tivesse acontecido" é um exercício cotidiano das pessoas. Porém, quando esses historiadores supracitados propõem a possibilidade de se pensar a história a partir das outras possibilidades de passado existentes, eles estão, em essência, fazendo um exercício retórico de pensar o passado, porém um passado diferente do que aconteceu, mas que devido às evidencias e conjunturas acabou não acontecendo.

\footnotetext{
24 "Those who defend the decision claim that it ended a bloody war that would have become far bloodier had the planned invasion of the Japanese home islands proved necessary. Although the primary consideration was saving American lives, according to this view, millions of Japanese also were spared the catastrophic effects of an invasion coupled with round-the-clock conventional bombing, naval bombardment, and blockade" (texto original).
} 
Essa questão é que torna a filosofia da história de Maddox ainda mais interessante. Ao propor um cálculo, estimativo, segundo ele, de quantos soldados estadunidenses teriam morrido, caso os EUA invadissem por terra e ar o Japão no final da Segunda Guerra Mundial, o autor está pensando não em outras possibilidades de passado, mas em uma justificativa jogada para o futuro de uma ação tomada no passado. Por isso, o futuro como justificativa é prerrogativa máxima da filosofia do futuro de Robert Maddox e suas proposições. Pois, ao falar de futuro, num sentido contrafactual, você pode construir os mais variados tipos de cenários, porém todos embasados em fontes que se encontram nesse passado, permitindo assim a reflexão sobre as várias possibilidades de agências e rumos da História e de como lidar com esse passado. Neste sentido:

A resposta à pergunta é muito simples: Devemos considerar como plausíveis ou prováveis apenas as alternativas que podemos mostrar com base em evidências contemporâneas que os contemporâneos realmente a consideram. (FERGUSON, 2000, p. 84)

Portanto, Robert James Maddox, ao escrever sobre o passado, principalmente sobre a bomba atômica, realiza um processo de estabelecimento de relações entre o passado, presente e futuro, no qual todos ficam subjugados de forma que seus argumentos retóricos permitam o estabelecimento de uma factualidade do passado que justifique ações tomadas pelos EUA. Neste sentido, o futuro exerce o papel de justificativa, de bode expiatório, aquele no qual se projetam diversos cenários e, como todos apontavam para cenários terríveis, a gloriosa nação estadunidense optou por escolher o cenário mais favorável a todos.

Neste sentido, para além da factualidade (que pode ser discutida, reinterpretada e pensada de outras formas), o futuro como justificativa permite não só corroborar e explicar os motivos que levaram os EUA a usar a bomba atômica - por parte de Maddox mas também, permitem pensar no caráter "divino", ou "cosmológico", como aponta Harvey (2004), do discurso nacional estadunidense de ser um povo com um destino manifesto, que pensa nos mais variados cenários futuros e sempre escolhe o melhor para todos. Assim, ao usar o futuro como justificativa, ele está justificando o ("glorioso") passado (tão fragmento e em eterna disputa). 


\section{Referências}

ALPEROVITZ, Gar. Atomic diplomacy: Hiroshima and Potsdam. New York: Simon and Schuster, 1965.

ANDERSON, Benedict. Comunidades imaginadas. São Paulo: Companhia das Letras, 2008.

ARMITAGE, David. Why politicians need historians. The Guardian. Londres, 7 de outubro de 2014.Disponível: <http://www.theguardian.com/education/2014/oct/o7/why-politiciansneed-historians $>$. Acesso em 24/03/2016.

ASADA, Sadao. The shock of the atomic bomb and Japan's decision to surrender: a reconsideration. Pacific Historical Review, Oakland (EUA), v. 67, n. 4., p. 477-512, nov., 1998.

BUNZL, Martin. Counterfactual history: a user's guide author(s). The American Historical Review, Oxford (EUA), v.109, n. 3, p. 845-8, Jun., 2004.

DIRK MOSES, A. Hayden white, traumatic nationalism and the public role of history. History and Theory, v. 44, n. 2, p. 311-332, 2005.

FERGUSON, Niall (Org.). Virtual history: alternatives and counterfactuals. New York (EUA): Basic Books, 2000.

FEUERBACH, Ludwig. Principles of the philosophy of the future. Indianapolis (USA): Hackett Publishing Company, 1986.

HARVEY, David. O novo imperialismo. São Paulo: Loyola. 2004

HUYSSEN, Andreas. En busca del futuro perdido: cultura y memoria en tempos de globalización. Buenos Aires: Fondo de Cultura Económica de Argentina S.A., 2007.

JACOBY, Russell. Os últimos intelectuais: a cultura americana na era da academia. São Paulo: Edusp, 1990.

KAMMEN, Michael. In the past lane: historical perspectives on American culture. Oxford: Oxford University Press, 1997.

KAMMEN, Michael. The historian's vocation and the State of the discipline in the United States. In: KAMMEN, Michael (Org.). The past before us: contemporary historical writing in the United States. Itahaca/London: Cornell University Press, 1980. 
KIERNAN, Victor. Estados Unidos o novo imperialismo: da colonização branca à hegemonia mundial. Rio de Janeiro: Record, 2009.

KOSELLECK, Reinhart. Futuro passado: contribuição à semântica dos tempos históricos. Rio de Janeiro: Contraponto/Editora da PUC-Rio, 2006.

LACAPRA, Dominick. Trauma, ausência, perdida. In: LACAPRA, Dominick. Escribir la historia, escribir el trauma. Buenos Aires: Nueva Visión, 2005. p. 65-104.

LIAKOS, Antonis. Utopian and historical thinking: interplays and transferences. Historien, Athens (GRE), v.7, 2007.

MADDOX, Robert (Org). Hiroshima in history: the myths of

revisionism. London/Columbia: University of Missouri Press, 2007.

MADDOX, Robert. The new left and the origins of the cold war. Princeton: Princeton Legacy Library, 1973.

MADDOX, Robert. Weapons for Victory: the Hiroshima cecision fifty years Later. Chicago: University of Missouri Press, 1995.

MADDOX, Robert. William E. Borah and American Foreign Policy. Baton Rouge: Louisiana State University Press, 1970.

MINOIS, George. História do futuro: dos profetas à prospectiva. Lisboa: Teorema, 2000.

MISCAMBLE, Wilson. The most controversial decision: truman, the atomic bombs and the defeat of Japan. Cambridge: Cambridge University Press, 2011.

NOVICK, Peter. That noble dream: the "objectivity question" and the American Historical Profession. New York: Cambridge University Press, 2005.

RODGERS, Daniel. The age of fracture. Princeton: Princeton University Press, 2011.

STALEY, David. A history of the future. History and Theory. Middletown (EUA), n. 41, p. 72-89, dez., 2002,

STEEL, Ronald. Did Anyone Start the Cold War? The New York Review, New York, set. 1971. Disponível em: <http://www.nybooks.com/articles/archives/1971/sep/02/did-anyonestart-the-cold-war/> Acesso em 07/01/2014. 
TURNER, Frederick Jackson. O significado da história. Traduzido e apresentado por Arthur Ávila. História, Franca, v.24, n.1, 2005. p.191-223. Disponível em:

<www.scielo.br/pdf/his/v24n1/a08v24n1.pdf>. Acesso em 10/06/2012.

WEST, Cornel. Questão de raça. São Paulo: Companhia das Letras, 1994.

WHITE, Hayden. The content of the form: narrative discourse and historical representation. Baltimore: The Johns Hopkins University Press, 1987.

WHITE, Hayden. The practical past. Evanston: Northwestern University Press, 2014.

Recebido em 30/06/2016 Aprovado em 10/11/2016 